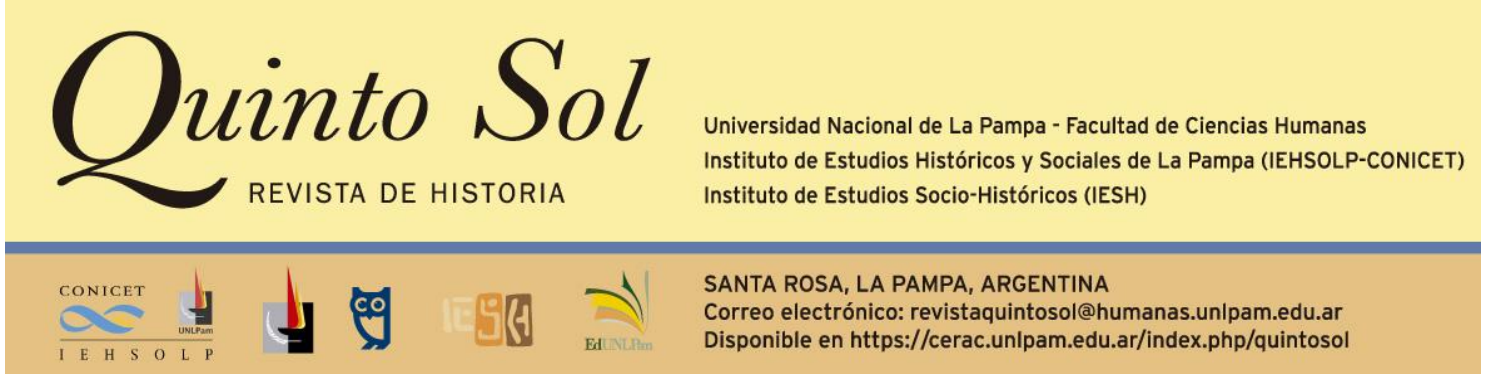

Quinto Sol, vol. 24, n 1, enero-abril 2020, ISSN 1851-2879, pp. 1-5

DOI: http://dx.doi.org/10.19137/qs.v24i1.3848

Esta obra se publica bajo licencia Creative Commons 4.0 Internacional. (Atribución-No ComercialCompartir lgual)

\title{
Florencia Garramuño. Brasil caníbal. Entre la Bossa Nova y la extrema derecha. Ciudad Autónoma de Buenos Aires: Paidós, 2019, 168 páginas.
}

\author{
Juan Lucca \\ Consejo Nacional de Investigaciones Científicas y Técnicas \\ Universidad Nacional de Rosario. Centro de Estudios Comparados. \\ Argentina \\ Correo electrónico: juanlucca@hotmail.com
}

Durante las últimas dos décadas, la historia política brasileña ha adquirido un creciente interés en las ciencias sociales y políticas en Argentina, tal vez como una forma elíptica para comprender las vicisitudes locales, bajo el candil de un país en creciente expansión y resonancia internacional desde la llegada del gobierno del Partido de los Trabajadores y la figura de Lula da Silva a la presidencia ${ }^{1}$. La vocación por poner en palabras castellanas los avatares lusitanos del vecino país, llevaron inclusive a que se produjera un enorme acervo de traducciones de obras brasileñas, bajo el intento de ofrecer retazos para construir una biografía ordenada o un "caminho

\footnotetext{
${ }^{1}$ Esta vocación por comprender e interpretar comparativamente a Brasil se visualiza en obras de reciente publicación como: Carlos Álvarez (2003); Marcelo Gullo (2005); Alejandro Grimson (2007); Mario Rapoport y Eduardo Madrid (2011); Daniel Amicci (2012); Amilcar Salas Oroño (2012); José Natanson (2014); Carlos Milani et al. (2014); Artiz Recalde (2016); Vicente Palermo (2016, 2018); Dolores Rocca Rivarola (2019); Juan Lucca, Esteban Iglesias y Cintia Pinillos (2019); entre otras.
} 
das pedras" ${ }^{\prime 2}$ que permita transitar la multiplicidad que encierra aquel país. En este marco, la aparición del libro de Florencia Garramuño, Brasil caníbal..., es un intento acertado por ofrecer parajes o destinos donde anclar en este archipiélago diverso y complejo de la historia brasileña del siglo XX y XXI, más que brindar una brújula para un tránsito apolíneo que clausure los sentidos o desoiga los cantos de sirena que trasuntan por la Odisea brasileña.

En esta publicación se entremezclan aproximaciones desde los estudios culturales y la literatura, la historiografía sobre el pasado reciente y la sociología, las observaciones participantes y la perplejidad de la experiencia en primera persona. Sin embargo, claramente estás observaciones están escritas a caballo de un presente que la inquieta por la radicalización y la llegada de un gobierno post autoritario de Jair Bolsonaro por un lado, y la proliferación de aristas que la han llevado a enamorarse de Brasil como un enigma, por el otro. Escrito con una pluma liviana, voraz, seductora y profusa, ofrece un derrotero panorámico, complejo y ligero sobre el devenir de ese país desde su configuración identitaria como Estado nación hasta su perplejidad actual como sociedad en crisis.

Así, Brasil caníbal..., es una lectura ineludible para quienes busquen abrir la caja de Pandora del vecino país, anhelando la esperanza de un futuro más auspicioso, a la espera de un presente más benigno, a partir de la recuperación de un pasado tropical y antropófago; pero, sobre todo, este libro es una lectura necesaria, para quienes tengan la vocación por comprender la magnitud de un territorio cuasi continental en el itinerario de sus últimos doscientos años. Es decir, este texto es una puerta de entrada necesaria para comprender, interpretar y valorar (o cuando no comparar implícitamente con sus pares latinoamericanos) a Brasil en tanto experiencia hipnótica de un caleidoscopio en movimiento. Para ello, la estructura del texto de Garramuño está ordenada en torno a cinco apartados, que recuperan fragmentos previamente publicados por la autora e innumerables aportes inéditos que hilvanan y condensan peldaños de una lectura que sea, en palabras de la profesora de la Universidad de San Andrés en Argentina, una vía de entrada a un "Brasil para principiantes".

El capítulo uno (Una cultura en los trópicos), presenta la contradicción inherente a la historia de Brasil, que puede ser imaginado tanto como vergel o paraíso -tal y como lo describiera Pero Vaz de Caminha- y también como páramo de civilización o tristes trópicos, especialmente en el marco de la llustración del siglo XVIII. En esta senda, la pregunta por el ser y la identidad, es un prisma que se desarrolla con esplendor durante la naciente república a finales del siglo XIX e inicios del siglo XX, fundamentalmente de la mano y pluma de ensayistas como Euclides da Cunha, Gilberto Freyre o Sergio Buarque de Holanda, entre otros. Este Brasil novo del siglo XX es un terreno en el que las herencias coloniales e imperiales conviven y se debaten con el alma salvaje y antropófaga del indio por un lado, y las marcas y designios de una sociedad de la esclavitud que se libera en manifestaciones como el candomble, el batuque o simplemente escapa hacia terrenos como la República de Palmares, por el otro.

\footnotetext{
2 En la jerga o argot brasileño, transitar el "caminho das pedras" alude a una forma más rápida y poco conocida, salvo por los experimentados, de desentrañar una situación o desandar un derrotero. Véase Vicente Palermo \& Rafael Mantovani (2008).
} 
Toda esta superposición dantesca de fragmentos multiformes que atraviesan en múltiples direcciones la historia de Brasil hasta el siglo $\mathrm{XX}$, pueden verse incluso retratados en el segundo capítulo de este libro ( $E /$ barroco), que da cuenta de las manifestaciones culturales como la "Caravana Modernista", el "Manifiesto Antropófago", entre otros, que en las primeras década del siglo XX vuelven al germen del momento barroco brasileño (con esplendor en las ciudades de Minas Gerais), para mostrar en carne viva la superposición de contradicciones que atraviesa al país.

El tercer apartado (Cultura popular y cultura erudita) trasvasa el debate desde la civilización o barbarie en la que se dirimía a inicios del siglo $\mathrm{XX}$, a un registro cultural en el que la música, el samba y el carnaval son los emblemas de esta nueva díada brasileña. Para la autora, la mistura entre danzas de salón europeas con la musicalidad de una sociedad esclavista que se aleja del pasado imperial, dan origen en Río de Janeiro al Samba, que se convierte desde las primeras décadas del siglo XX en un "efigie que irradia [...] la esencia nacional" (p. 66). Sin embargo, Garramuño muestra cómo esta mistura fina de lo sacro y profano, con los rasgos europeos, el andar indoamericano y el pulso africano, se reedita nuevamente en el carnaval, en tanto expresión con un encastre particular de cada ciudad, pero universal al país como terreno identitario. Por último, la autora evoca al movimiento de la Música Popular Brasileña (MPB) en general, y a la Bossa Nova en particular, para mostrar cómo se hilvana una vocación telúrica con una pretensión global, una innovación musical local con capacidad para ser exportada internacionalmente.

En la cuarta sección (Modernidad e inserción internacional) la autora desanda el camino de dos expresiones estéticas de enorme valía, como son el Manifiesto Antropófago de los años '20 y la Tropicalia de los '60, que si bien salen al encuentro de la identidad brasileña, lo hacen teniendo presente al otro, lo ajeno o aquellos que quedan perplejos por fuera del yo. Si la Antropofagia "...supone incorporación, desmembramiento, reinterpretación e invención" (p. 92), Tropicalia implica "...inscribir conquistas experimentales brasileñas en pie de igualdad con el debate internacional [para] lograr escapar de la exotización de lo brasileño" (p. 94). Uno y otro movimiento, tienen la particularidad de ser momentos "corales" en el mundo de la cultura, puesto que convergen múltiples expresiones artísticas como el cine, teatro, literatura, música, arquitectura, entre otras. El ícono de esta experiencia endógena, pero inscrita en una modernidad global, es la construcción de Brasilia de la mano de Juscelino Kubistchek entre 1954 y 1960. Si bien la nueva capital implicaba el pasaje desde un Brasil utópico al futuro posible, la autora recupera un interrogante similar al que se hiciera Bertolt Brecht cuando se preguntaba: "¿Adónde fueron los albañiles la noche que terminó de construirse la muralla china?" Parte de la respuesta se encuentra en este caso en la favela, no solo como epicentro de la hacinación y el calvario demográfico, sino también como laboratorio para nuevas expresiones culturales y políticas como las de Carolina María de Jesús o Marielle Franco.

El último capítulo (El país del futuro y la promesa que no fue) da cuenta del derrotero histórico y político desde el golpe de Estado de 1964, a través del sueño de "otro Brasil posible" que durante la década de 1980 y 1990 se configura de la mano del proyecto político del Partido de los Trabajadores, pasando por el tumultuoso despertar que implicó el juicio político a la presidenta Dilma Roussef o la prisión a Lula da Silva, hasta finalmente arribar al amanecer de la pesadilla que se inicia con la llegada de Bolsonaro al comando político de la República Federativa de Brasil. En este último 
apartado, especialmente al acercarse al presente, la voz en primera persona de la autora comienza a hacerse notar, no solo por haber sido flaneur de este período de su historia, sino también por su esfuerzo para no "soltarle la mano" a Brasil en un momento en el que, como lo enuncia el párrafo final de este libro, el odio ocupa la escena y el amor es el único "descanso a la locura".

Brasil caníbal... está escrito desde la perplejidad crítica del tiempo presente brasileño, con la maestría de quien conoce desde los rizomas de la cultura las pulsaciones de lo político, económico y social, motivo por el cual es una vía de entrada sutil y frondosa a un terreno que conjuga: la luz y la sombra de un pasado colonial, la esperanza y la espera de una herencia esclavista, la rebeldía y los estigmas de una historia amerindia, la civilización y la barbarie de una nueva república, el folklore y la modernidad de una cultura en ciernes, la flama del futuro y las cenizas del pasado en un presente que encandila por el fuego.

\section{Referencias bibliográficas}

1. Álvarez, C. (Comp.) (2003). La Argentina de Kirchner y el Brasil de Lula. Buenos Aires, Argentina: Prometeo.

2. Amicci, D. (2012). Argentina-Brasil, una amistad desarrollista. Villa María, Córdoba, Argentina: Editorial Universitaria Villa María.

3. Grimson, A. (Comp.) (2007). Pasiones nacionales. Política y cultura en Brasil y Argentina. Buenos Aires, Argentina: Editora y Distribuidora Hispano Americana S. A.

4. Gullo, M. (2005). Argentina-Brasil: la gran oportunidad. Buenos Aires, Argentina: Biblios.

5. Lucca, J., Iglesias, E. y Pinillos, C. (2019). Política brasileña en español. De la crisis al impeachment. Paraná, Entre Ríos, Argentina: Editorial de la Universidad de Entre Ríos.

6. Milani, C. et al. (2014). Atlas da política externa brasileira. Buenos Aires, Argentina: Consejo Latinoamericano de Ciencias Sociales.

7. Natanson, J. (2014). El milagro brasileño. Buenos Aires, Argentina: Debate.

8. Palermo, V. (2016). La alegría y la pasión. Relatos brasileños y argentinos en perspectiva comparada. Buenos Aires, Argentina: Katz.

9. Palermo, V. (2018). Instituciones políticas brasileñas. Estabilidad y crisis del proceso político contemporáneo. Buenos Aires, Argentina: Katz.

10. Palermo, V. \& Mantovani, R. (2008). O caminho das pedras. Manual de gíria brasileña. Colección claves para todos. Buenos Aires, Argentina: Capital Intelectual.

11. Rapoport, M. y Madrid, E. (2011). Argentina-Brasil. De rivales a aliados. Política, economía y relaciones bilaterales. Buenos Aires, Argentina: Capital Intelectual.

12. Recalde, A. (2016). Estudios sobre Brasil. Buenos Aires, Argentina: Punto de Encuentro/Universidad Nacional Arturo Jauretche. 
13. Rocca Rivarola, D. (2019). Militar en el gobierno. Generaciones de militancia juvenil en los gobiernos argentinos y brasileros (2003-2015/2016). Buenos Aires, Argentina: Grupo Editor Universitario.

14. Salas Oroño, A. (2012). Ideología y democracia: intelectuales, partidos políticos y representación partidaria en Argentina y Brasil desde 1980 al 2003. Ciudad Autónoma de Buenos Aires, Argentina: Pueblo Heredero Editorial. 